\title{
GEOGRAPHICAL VARIATION IN MORPHOLOGICAL LEAF TRAITS OF Huperzia serrata (Lycopodiaceae) FROM VIETNAM
}

\author{
Nguyen Thi Ai Minh ${ }^{1}$, Le Ngoc Trieu ${ }^{1}$, Nong Van Duy ${ }^{2}$, Tran Van Tien ${ }^{1, *}$ \\ ${ }^{1}$ Dalat University \\ ${ }^{2}$ Tay Nguyen Institute for Scientific Research, VAST, Vietnam
}

Received 21 October 2019, accepted 24 December 2019

\begin{abstract}
Morphological leaf traits can be used to assess adaptive responses of plants to environmental conditions. To assess how the representation of Huperzia serrata leaf traits, such as leaf length (LL), leaf width (LW) and leaf area (LA) response to changes in mean annual temperature (MAT), sunshine duration (SuH), mean annual precipitation (MAP), air humidity (Hu), intraspecific variation of the morphological leaf traits of the species was analyzed along a geographical gradient of Vietnam. The results showed that among the three populations at the three sites, leaf sizes increased with MAT and MAP.
\end{abstract}

Keywords: Huperzia serrata, climatic factors, morphological leaf traits, Vietnam.

Citation: Nguyen Thi Ai Minh, Le Ngoc Trieu, Nong Van Duy, Tran Van Tien, 2019. Geographical variation in morphological leaf traits of Huperzia serrata (Lycopodiaceae) from Vietnam. Academia Journal of Biology, 41(4): 101-110. https://doi.org/10.15625/2615-9023/v41n4.14719.

*Corresponding author email: tvtien117@yahoo.com

(C2019 Vietnam Academy of Science and Technology (VAST) 


\section{INTRODUCTION}

Plant growth is affected by numerous environmental factors, including water shortage and excess, temperature, nutrient availability, and light (Diaz et al., 1998). The influence of environmental factors on plant growth can be either direct, via the impact of physical conditions on primary growth processes or indirect due to developmental adaptation (Choat et al., 2007). Phenotypic plasticity is a major mode of adaptation in plants (Sultan, 1995). Consequently, morphological leaf traits could reflect the adaptation of plants to their environment (Kessler et al., 2007) as they can influence fitness of plant (Donovan et al., 2011). Among environmental conditions, climate, which is a combination of some important ecological factors, plays an important role in adaptations of plants as it creates selection scenarios (Etterson \& Shaw, 2001).

Many studies showed evidence of plastic response to key ecological factors of several morphological leaf traits (Arens, 2001; Donohue et al., 2000; Dudley and Schmitt, 1996; Giełwanowska et al., 2012). However, most studies of these kinds were conducted among angiosperms and ferns while fernallies received little attention.

Huperzia serrata (Thunb. ex Murray) Trevis. is a club moss, which is widely distributed in temperate and tropical zones including Chinese, Bhutan, Cambodia, India, Indonesia, Japan, Korea, Laos, Malaysia, Myanmar, Nepal, Philippines, Russia, Sri Lanka, Thailand, Vietnam, Australia, Central America and Pacific islands (Jaswinder et al., 2016; Wang et al., 2011). In Vietnam, this species is only available on high mountains with altitude from $1000 \mathrm{~m}$ to $1500 \mathrm{~m}$, including Lao Cai, Cao Bang, Quang Tri, Quang Nam, Khanh Hoa, Lam Dong Province (BVN Group). Widely distributed capacity of $H$. serrata represented evidence of their adaptive ability to a broad range of local conditions (Joshi et al., 2001) and provided an opportunity to analyze phenotypic variation along large geographical gradients (Villellas et al., 2014). Phenotypic variation could be reflected in the morphological characters of the leaves, including width, length and area (Kessler et al., 2007). However, parameterizations of the special variation in the leaf exchange characteristics within geographical gradients have not been evaluated. The focus of this study is to assess how the representation of $H$. serrata leaf traits such as leaf length, leaf width, leaf area response to changes in climatic factors along a geographical gradient of Vietnam.

\section{MATERIALS AND METHODS}

\section{Study local populations and sampling}

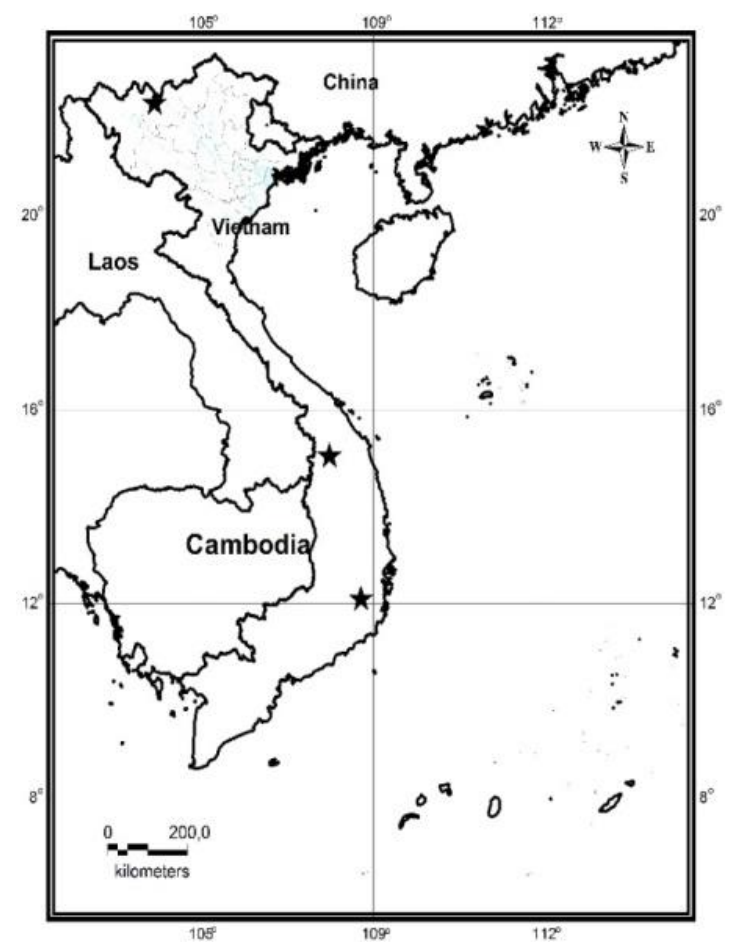

Figure 1. Distribution of the 3 sampling sites (provinces) of $H$. serrata leaves in Vietnam.

The stars represent the origin growth area of the species where leaves were collected

Samples were collected at high mountains in provinces documented to have $H$. serrata in Vietnam, including Hoang Lien National Park (Lao Cai Province, 22 408'946”N; $103^{\circ} 838^{\prime} 908^{\prime \prime E)}$; Ngoc Linh National Reserve (between Quang Nam and Kon Tum Province, $\left.15^{\circ} 071^{\prime} 650^{\prime \prime} \mathrm{N}, 107^{\circ} 973^{\prime} 969^{\prime \prime} \mathrm{E}\right)$; and Bidoup 
National Park (Lam Dong Province, $12^{\circ} 100^{\prime} 364^{\prime \prime N}, 108^{\circ} 664^{\prime 4} 431$ ”E) (Fig. 1).

At each study site, which is distribution area of each population of $H$. serrata, 30 samples were randomly collected, from 3 to 10 sites in each population. Each sample had to have at least two gemmiphore layers and was restored in a zip bag. Sampled individuals in the three populations were signed from HuL21 to HuL50 for Hoang Lien National Park population (signed as Hoang Lien population); HuK21 to HuK50 for Ngoc Linh National Reserve population (signed as Ngoc Linh population) and HuD21 to HuD50 for Bidoup National Park population (signed as Bidoup population).

\section{Leaf material}

All measurements in analyzing morphological leaf traits were conducted on 30 individuals in each population and on 90 individuals in total. Using gemmiphore layers to identify yearly growth boundary of shoots of each individual (Wang et al., 2011). The numbers of annual growth shoots in each population identified by using gemmiphore layers were recorded (table 1). Accordingly, the number of shoots growing in 4 years, from 2013 to 2016, was adequate for statistical analysis. On each annual shoot of each individual, 3 to 5 undamaged big leaves are collected, and scanned by flatbed scanner HP4670. Using scanned photographs to measure leaf size by ImageJ $1.52 \mathrm{~b}$ software (Abramoff et al., 2004). Leaf size measures collected were leaf length (LL), leaf width (LW) and leaf area (LA). LA is the most common metric of leaf size and is defined as the one-side of an individual leaf, expressed in $\mathrm{mm}^{2}$; LW is an additional trait of ecological interest related to leaf size, measured as the maximum diameter of an imaginary circle that can be fitted anywhere within a leaf and LL is blade length of a leaf (Pérez-Harguindeguy et al., 2013).

Table 1. The number of annual growth shoots in each population identified by using gemmiphore layers

\begin{tabular}{|c|c|c|c|c|c|c|c|c|c|c|c|}
\hline \multirow[b]{2}{*}{ Year } & \multicolumn{3}{|c|}{ Population } & \multirow[b]{2}{*}{ Year } & \multicolumn{3}{|c|}{ Population } & \multirow[b]{2}{*}{ Year } & \multicolumn{3}{|c|}{ Population } \\
\hline & $\begin{array}{c}\text { Hoang } \\
\text { Lien } \\
\end{array}$ & $\begin{array}{l}\text { Ngoc } \\
\text { Linh }\end{array}$ & Bidoup & & $\begin{array}{c}\text { Hoang } \\
\text { Lien }\end{array}$ & $\begin{array}{l}\text { Ngoc } \\
\text { Linh }\end{array}$ & Bidoup & & $\begin{array}{c}\text { Hoang } \\
\text { Lien }\end{array}$ & $\begin{array}{l}\text { Ngoc } \\
\text { Linh }\end{array}$ & Bidoup \\
\hline 2009 & - & - & 1 & 2012 & 1 & 1 & 8 & 2015 & 29 & 30 & 30 \\
\hline 2010 & - & - & 2 & 2013 & 8 & 11 & 15 & 2016 & 30 & 30 & 30 \\
\hline 2011 & - & - & 5 & 2014 & 21 & 22 & 18 & 2017 & 17 & - & - \\
\hline
\end{tabular}

\section{Climatic variability of populations}

Meteorological data were obtained for all three populations from databases of meteorological stations closest to the distributed area of each population, which were Sapa station (Lao Cai Province), Tra My station (Quang Nam Province) and Dalat station (Lam Dong Province). At each station, mean annual air temperature (MAT), mean annual precipitation (MAP), annual sunshine duration $(\mathrm{SuH})$, annual air humidity $(\mathrm{H})$ were obtained. As leaves were collected on annual growth shoots in 4 years, from 2013 to 2016, climatic variables of the three study populations were calculated on database of the four years denoted.

\section{Data analysis}

Statistical analyses were conducted by STATGRAPHICS Centurion XV Version 15.1.02 software. First, the difference of leaf size measures as well as climatic variables among the three populations were tested and compared by one-way ANOVA and Least Significant Difference (LSD) to determine the changing trends of leaf size and climatic variables along with the latitudinal gradient of Vietnam. Second, Pearson's correlation test was performed to test the relationship between leaf size measures and climatic variables. Third, simple regression models were constructed to describe the linear relationship between each pair of leaf measure and climatic variable. 
Redundancy analysis (RDA) was used to determine the relative contribution of the measured climatic factors to leaf trait measurements of $H$. serrata. RDA was performed using XLSTAT software version 2018.1 (Addinsoft, 2018).

Table 2. Climatic variables obtained were mean annual air temperature (MAT), and mean annual precipitation (MAP), annual sunshine duration $(\mathrm{SuH})$ and annual air humidity $(\mathrm{H})$

\begin{tabular}{|c|c|c|c|c|c|}
\hline Population & Year & MAT $\left({ }^{\circ} \mathrm{C}\right)$ & SuH (hours) & MAP $(\mathrm{mm})$ & Hu $(\%)$ \\
\hline \multirow{4}{*}{ Hoang Lien } & 2013 & 14.96 & 1359.00 & 2733.50 & 87.00 \\
\cline { 2 - 6 } & 2014 & 15.43 & 1469.00 & 2431.60 & 88.00 \\
\cline { 2 - 6 } & 2015 & 16.30 & 1678.00 & 2491.60 & 84.42 \\
\cline { 2 - 6 } & 2016 & 16.48 & 1643.00 & 2516.60 & 82.75 \\
\cline { 2 - 6 } & Average & $15.77^{\mathrm{a}}$ & $1537.25^{\mathrm{a}}$ & $2543.33^{\mathrm{a}}$ & $85.54^{\mathrm{a}}$ \\
\hline \multirow{5}{*}{ Ngoc Linh } & 2013 & 24.80 & 1619.00 & 4043.00 & 88.00 \\
\cline { 2 - 6 } & 2014 & 25.10 & 1992.00 & 3416.00 & 86.00 \\
\cline { 2 - 6 } & 2015 & 25.20 & 2176.00 & 4002.00 & 87.00 \\
\cline { 2 - 6 } & 2016 & 25.40 & 1819.00 & 5330.00 & 88.00 \\
\cline { 2 - 6 } & Average & $25.13^{\mathrm{c}}$ & $1901.50^{\mathrm{b}}$ & $4197.75^{\mathrm{b}}$ & $87.25^{\mathrm{b}}$ \\
\hline & 2013 & 18.40 & 2071.00 & 2029.00 & 85.00 \\
\cline { 2 - 6 } & 2014 & 18.20 & 2109.00 & 2072.00 & 80.00 \\
\cline { 2 - 6 } & 2015 & 18.50 & 2244.00 & 1955.00 & 84.00 \\
\cline { 2 - 6 } & 2016 & 18.50 & 2109.00 & 2029.00 & 86.00 \\
\cline { 2 - 6 } & Average & $18.39^{\mathrm{b}}$ & $2133.25^{\mathrm{b}}$ & $2021.25^{\mathrm{a}}$ & $83.33^{\mathrm{a}}$ \\
\hline
\end{tabular}

Notes: MAT (F-ratio $=490.71, \mathrm{P}<0.01)$; SuH $($ F-ratio $=12.75, \mathrm{P}<0.01)$; MAP $($ F-ratio $=23.07, \mathrm{P}<0.01)$; $\mathrm{Hu}(\mathrm{F}-\mathrm{ratio}=3.16, \mathrm{P}<0.1)$.

\section{RESULTS}

\section{Climate factors}

ANOVA analysis of MAT, SuH, MAP and $\mathrm{Hu}$ showed that those measures were statiscally significant differences between sample sites. However, Fisher's least significant difference (LSD) procedure indicated that except for MAT, no significant differences were found between Hoang Lien and Bidoup in MAP and $\mathrm{Hu}$; and either Ngoc Linh and Bidoup in SuH. In the four years, it was Hoang Lien where had the lowest MAT $\left(15.77^{\circ} \mathrm{C}\right)$, which was lower than Bidoup $\left(18.39^{\circ} \mathrm{C}\right)$ and Ngoc Linh $\left(25.13^{\circ} \mathrm{C}\right)$. For $\mathrm{SuH}$, Bidoup ranked the first (2133.25 hours) while Ngoc Linh (1901.50 hours) and Hoang Lien (1537.25 hours) ranked the second and the third. For MAP, the measure in Ngoc Linh was the highest $(4197.75 \mathrm{~mm})$ which was much higher than that of Hoang Lien (2543.33 mm) and LD (2021.25 mm). For Hu, Fisher's LSD procedure proved that there were no significant differences between Bidoup and Hoang Lien and either Hoang Lien and Ngoc Linh. Nevertheless, there was a statistically significant difference for $\mathrm{Hu}$ between Bidoup and Ngoc Linh. Moreover, it is noticeable that $\mathrm{Hu}$ of the three sites were very high (higher than $83 \%$ ). Consequently, it can be suggested that H.serrata required humid air. In other words, habitat of $H$. serata is characterized by high air humidity.

\section{Leaf variability of populations}

Leaf variability of three populations of Vietnam, as well as climatic variables of the three study populations was investigated through statistical analysis of 90 qualitative leaf morphological traits of the four years. Among the leaf morphological traits, leaf length, leaf width and leaf area were observed (table 3). 
Geographical variation in morphological leaf traits

Table 3. Leaf size measures of the three local studied populations in four years (2013-2016)

\begin{tabular}{|c|c|c|c|c|c|c|c|c|c|}
\hline \multirow[b]{2}{*}{ Year } & \multicolumn{3}{|c|}{ LL (mm) } & \multicolumn{3}{|c|}{$\mathrm{LW}(\mathrm{mm})$} & \multicolumn{3}{|c|}{$\mathrm{LA}\left(\mathrm{mm}^{2}\right)$} \\
\hline & $\begin{array}{l}\text { Hoang } \\
\text { Lien }\end{array}$ & $\begin{array}{l}\text { Ngoc } \\
\text { Linh }\end{array}$ & Bidoup & $\begin{array}{c}\text { Hoang } \\
\text { Lien }\end{array}$ & $\begin{array}{l}\text { Ngoc } \\
\text { Linh }\end{array}$ & Bidoup & $\begin{array}{l}\text { Hoang } \\
\text { Lien }\end{array}$ & Ngoc Linh & Bidoup \\
\hline 2013 & $\begin{array}{c}11.09 \pm \\
2.75\end{array}$ & $\begin{array}{c}13.49 \pm \\
3.91\end{array}$ & $\begin{array}{c}11.97 \pm \\
3.61\end{array}$ & $\begin{array}{c}2.70 \pm \\
0.96\end{array}$ & $\begin{array}{c}3.73 \pm \\
0.82\end{array}$ & $2.51 \pm 1.24$ & $\begin{array}{c}22.27 \pm \\
11.30\end{array}$ & $\begin{array}{c}33.28 \pm \\
16.28\end{array}$ & $\begin{array}{c}21.05 \pm \\
14.46\end{array}$ \\
\hline 2014 & $\begin{array}{c}11.67 \pm \\
3.88\end{array}$ & $\begin{array}{c}14.35 \pm \\
4.74\end{array}$ & $\begin{array}{c}12.70 \pm \\
5.16\end{array}$ & $\begin{array}{c}2.96 \pm \\
1.06\end{array}$ & $\begin{array}{c}3.86 \pm \\
0.73\end{array}$ & $2.74 \pm 1.37$ & $\begin{array}{c}26.48 \pm \\
16.65\end{array}$ & $\begin{array}{c}31.86 \pm \\
14.93\end{array}$ & $\begin{array}{c}23.46 \pm \\
17.78\end{array}$ \\
\hline 2015 & $\begin{array}{c}10.67 \pm \\
3.54\end{array}$ & $\begin{array}{c}14.36 \pm \\
4.78\end{array}$ & $\begin{array}{c}12.12 \pm \\
4.36\end{array}$ & $\begin{array}{c}2.92 \pm \\
1.20\end{array}$ & $\begin{array}{c}3.70 \pm \\
0.92\end{array}$ & $2.61 \pm 1.24$ & $\begin{array}{c}20.92 \pm \\
13.01\end{array}$ & $\begin{array}{c}30.10 \pm \\
14.65\end{array}$ & $\begin{array}{c}22.08 \pm \\
16.19\end{array}$ \\
\hline 2016 & $\begin{array}{c}10.36 \pm \\
3.89\end{array}$ & $\begin{array}{c}16.43 \pm \\
5.22\end{array}$ & $\begin{array}{c}10.18 \pm \\
3.26\end{array}$ & $\begin{array}{c}2.60 \pm \\
1.14\end{array}$ & $\begin{array}{c}3.97 \pm \\
1.01\end{array}$ & $2.19 \pm 0.99$ & $\begin{array}{c}20.55 \pm \\
14.19\end{array}$ & $\begin{array}{c}40.43 \pm \\
19.66\end{array}$ & $\begin{array}{c}13.45 \pm \\
8.12\end{array}$ \\
\hline Average & $\begin{array}{c}10.77 \pm \\
3.64^{\mathrm{a}}\end{array}$ & $\begin{array}{c}14.86 \pm \\
4.89^{\mathrm{b}}\end{array}$ & $\begin{array}{c}11.57 \pm \\
4.23^{\mathrm{a}}\end{array}$ & $\begin{array}{l}2.80 \pm \\
1.14^{\mathrm{a}}\end{array}$ & $\begin{array}{l}3.83 \pm \\
0.90^{\mathrm{b}}\end{array}$ & $2.48 \pm 1.21^{\mathrm{a}}$ & $\begin{array}{l}21.50 \pm \\
13.33^{\mathrm{a}}\end{array}$ & $\begin{array}{l}33.99 \pm \\
17.05^{\mathrm{b}}\end{array}$ & $\begin{array}{l}19.39 \pm \\
14.75^{\mathrm{a}}\end{array}$ \\
\hline
\end{tabular}

Notes: LL (F-ratio = 14.92, P<0.01); LW (F-ratio = 56.02, P<0.01); LA (F-ratio = 13.70, P<0.01).

ANOVA revealed that all morphological leaf traits significantly varied across all the three populations considered (Table 3). The proportion of variance of LL, LW and LA within individuals in the same population ranged from $33.1 \%$ to $36.6 \%, 23.9-48.7 \%$ and $53.6-80.3 \%$, respectively. Among the three populations, all three leaf traits examined in Bidoup population varied the most while those of Hoang Lien population varied the least. In other words, Bidoup population showed higher leaf trait plasticity than Hoang Lien population and in turn, leaf traits of Hoang Lien population were more plastic than those of Ngoc Linh population.

At population level, in the four years, leaves of Hoang Lien population were the smallest in 2016 and the biggest in 2014. Noticeably, MAT and MAP in the habitat of Hoang Lien population in 2016 were high $\left(16.48^{\circ} \mathrm{C}\right.$ and $2516.6 \mathrm{~mm}$, respectively) and in 2014 were relatively low $\left(15.43^{\circ} \mathrm{C}\right.$ and 2431.6 $\mathrm{mm})$. However, Hu of Hoang Lien population in 2016 was considerably low $(82.75 \%)$ compared with that in 2014 (88.00\%). Consequently, it can be implied that growth of H.serrata leaf was restricted by air humidity.

As for Ngoc Linh population, it is clear that MAT, MAP and $\mathrm{Hu}$ accelerated the growth of leaf as three leaf measurements in 2016 were the highest, which were agreed with the highest figure of MAT, MAP and $\mathrm{Hu}$ in the year.

Similar to Hoang Lien population, $\mathrm{Hu}$ in Bidoup population differed moderately (80$86 \%)$. Moreover, MAT and MAP fluctuated minimally among the four years. However, different from Hoang Lien population, leaves in Bidoup population were the smallest in 2016 when Hu peaked in the four years $(86 \%)$ and were the largest in 2014 when $\mathrm{Hu}$ was the lowest $(80 \%)$. A reasonable explanation for this phenomenon might be wet season duration. In 2014, Bidoup population habitat had 7 consecutive months with MAP higher than $150 \mathrm{~mm}$ while in other years, wet season was suspended by months with MAP lower than $150 \mathrm{~mm}$. It is 2016 that wet season of Lam Dong province was split seriously. In this year, the wet season was interrupted three times so that the wet period in this year could not last more than 2 months. In particular, wet months included April, June and July, September and October, and December.

At species level, the mean LL ranged from $10.77 \mathrm{~mm}$ (Hoang Lien population) to 14.86 $\mathrm{mm}$ (Ngoc Linh population); the mean LW ranged from $2.48 \mathrm{~mm}$ (Bidoup pop.) to 3.83 $\mathrm{mm}$ (Ngoc Linh population); whereas the mean LA ranged from $19.39 \mathrm{~mm}^{2}$ (Bidoup population) to $33.99 \mathrm{~mm}^{2}$ (Ngoc Linh pop.). Ngoc Linh pop. exhibited the highest LL, LW and LA, whereas Hoang Lien and Bidoup populations did the lowest. $H$. serrata grew in Hoang Lien with the lowest MAT $\left(15.77^{\circ} \mathrm{C}\right)$ had the shortest leaves while those grew in Ngoc Linh with the highest MAT $\left(25.13^{\circ} \mathrm{C}\right)$ had the longest ones.

Different from LL, LW and LA of the three populations were consistent with MAP, especially MAP in rain season. As for LW, this measurement gradually increased from 
Bidoup population to Hoang Lien and Ngoc Linh populations $(2.5 \mathrm{~mm}, 2.8 \mathrm{~mm}, 3.8 \mathrm{~mm}$, respectively). Those figures were corresponding with MAP (2021.25 mm, $2543.33 \mathrm{~mm}, 4197.75 \mathrm{~mm}$, respectively) as well as MAP per month in rain season in the three sites $(253.3 \mathrm{~mm}, 335.4 \mathrm{~mm}, 544.7 \mathrm{~mm}$, respectively).

Similar to LW, LA also gradually increased from Bidoup population to Hoang Lien population and Ngoc Linh population $\left(21.0 \mathrm{~mm}^{2}, 22.3 \mathrm{~mm}^{2}, 35.3 \mathrm{~mm}^{2}\right.$, respectively) which were corresponding with MAP (2021.25 mm, $2543.33 \mathrm{~mm}, 4197.75 \mathrm{~mm}$, respectively) as well as MAP per month in rain season in the three sites $(253.3 \mathrm{~mm}, 335.4$ $\mathrm{mm}, 544.7 \mathrm{~mm}$, respectively). As expected, the result showed that both MAP and MAT affected leaf size of $H$. serrata. MAT had strong effect on LL while MAP was the factor that influenced LW and LA.
Among the three populations, Ngoc Linh population had the biggest leaves because the population is distributed in the north central part, which has monsoon tropical climate with cool winter and summer-autumn-winter rains and common cloudiness, the MAT is higher (Table 2). It is recognized that the trend of $H$. serrata species grown in regions with higher MAP and MAT had higher leaf length as well as leaf width and leaf area.

Multiple variable analysis result revealed that the mean LL, LW, and LA of $H$. serrata leaves had a significantly positive linear relationship with MAT $(\mathrm{r}=0.8663, \mathrm{P}=$ $0.0003 ; r=0.8466, P=0.0005 ; r=0.7704, R$ $=0.0034$, respectively) and MAP $(\mathrm{r}=0.8384$, $\mathrm{P}=0.0007 ; \mathrm{r}=0.8997, \mathrm{P}=0.0001 ; \mathrm{r}=0.9039$, $\mathrm{R}=0.0001$, respectively). The linear models of MAT explain $75 \%$ of leaf length variability, $72 \%$ that of leaf width and $59 \%$ that of leaf area (Fig. 2). As for MAP, the figures were $70 \%, 81 \%$ and $82 \%$, respectively (Fig. 2).
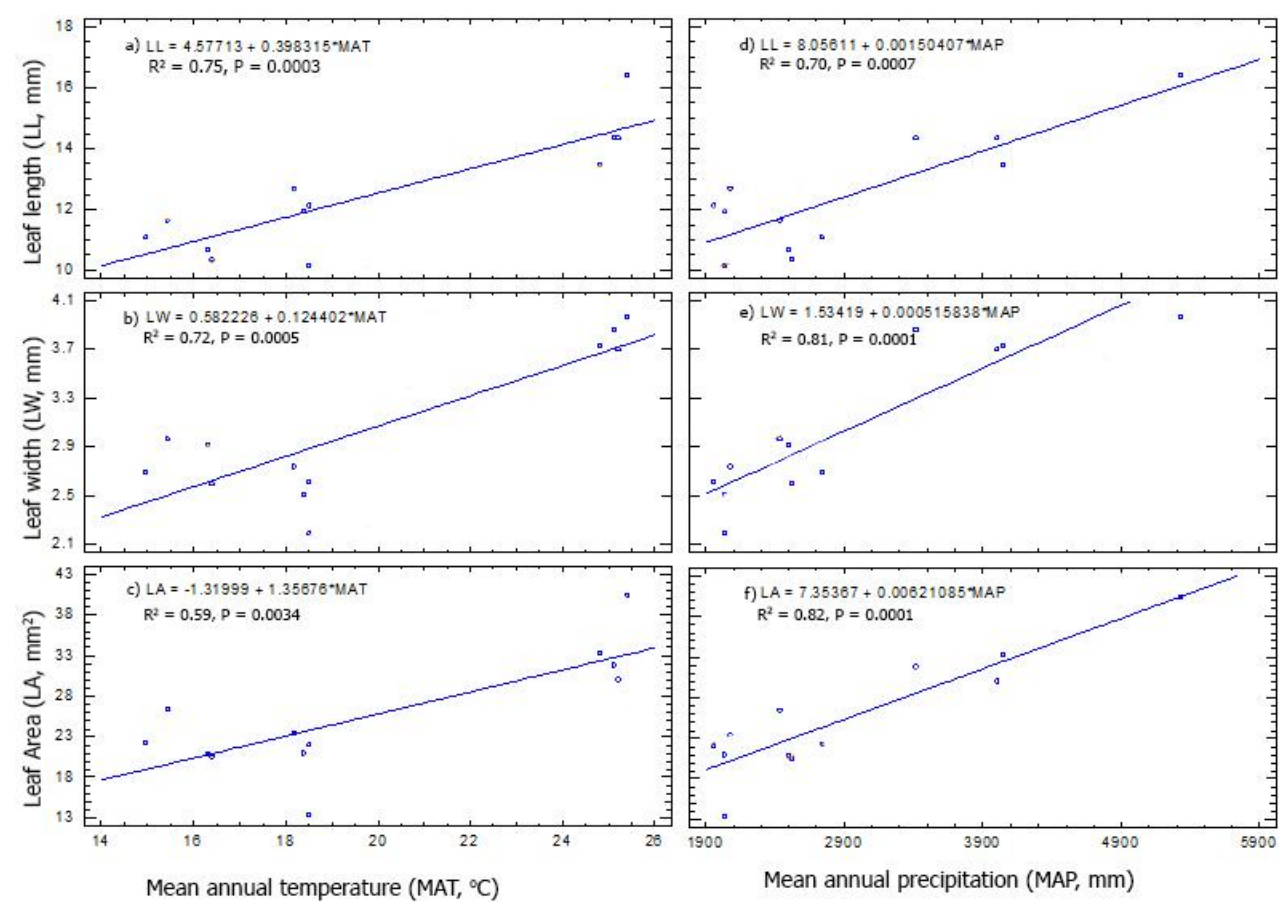

Figure 2. Relationships between morphological leaf trait of leaf length (LL), leaf width (LW), and leaf area (LA) and the climatic factors of mean annual temperature (MAT) and mean annual precipitation (MAP) in three sampling sites across Vietnam. Each square represents 1 of the 12 values of morphological leaf traits measured in the 3 sampling sites in the four years (2013-2016) 


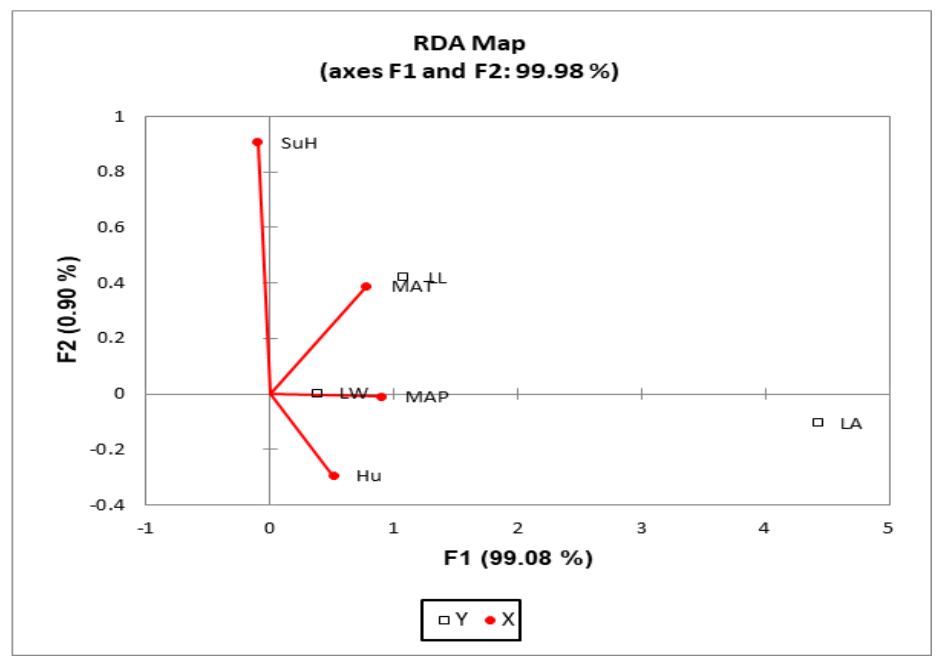

Figure 3. Correlation coefficients between leaf traits of three $H$. serrata populations and climatic factors. X-climatic factors, Y- Leaf trait measurements

Leaf traits of the three $H$. serrata populations from Vietnam were influenced by the following climatic factors: MAT, MAP, SuH and $\mathrm{Hu}$ (Fig. 3). Correlation analyses proved that there were positive (MAT, MAP) and negative ( $\mathrm{SuH}$ and $\mathrm{Hu})$ correlations between leaf traits of H.serrata populations and climatic factors (Fig. 3). However, of the four climatic variables, only MAT and MAP significantly correlated with leaf trait measurement according to multiple variable analyses. RDA showed that the four climate environmental variables (MAT, MAP, $\mathrm{SuH}$ and $\mathrm{Hu}$ ) together explained $84.05 \%$ of the total variation in the data, and with figure 3 was explaining $99.08 \%$ and $0.9 \%$ of the total variation. This result indicates that some other climatic factors that were not considered in this study also contribute to the unexplained variation (Huang et al., 2016) and MAT and MAP were the major factors that affected leaf traits.

\section{DISCUSSION}

The relationships between morphological leaf traits and climatic conditions have been emphasized for at least a century (Wright et al., 2004). Climatic parameters frequently used in studies dealing with the relationship with leaf size and shape were MAT, MAP and $\mathrm{CO}_{2}$ or temperature- and precipitation-related parameters (Traiser et al., 2005). Those parameters were major limiting factors for the distribution of plants (Traiser et al. 2005).

Leaves vary tremendously in their size (Sack et al., 2003) and results of experimental studies as well as direct sampling of leaves in the field studies proved that temperature and rainfall had great impact on leaf size (Flann et al., 2002; Li et al., 2015). Results of this study showed that the size of leaves was strongly linearly related to temperature and rainfall (Fig. 2). There are biological bases for these relationships (Field et al., 2005; Royer and Wilf, 2006; Lawren and Sack, 2013; Traiser et al., 2005). Plant growing at the sites which have dry and cold climate tended to have smaller leaves to reduce evaporation while larger leave were more common in more humid areas (Li et al., 2015). For that reason, LA of H.serrata in Bidoup which had dry and cold climate (MAP $=2021.25 \mathrm{~mm}$ and MAT $\left.=18.39^{\circ} \mathrm{C}\right)$ was the lowest $(\mathrm{LA}=19.39$ $\mathrm{mm}^{2}$ ) while that of Hoang Lien which had much colder climate $\left(\mathrm{MAT}=15.77^{\circ} \mathrm{C}\right.$ ) but more humid (MAP $=2543.33 \mathrm{~mm}$ ) was higher. However, LA of H.serrata in a site warm and humid like Ngoc Linh (MAT = $25.13^{\circ} \mathrm{C}$, MAP $=4197.75 \mathrm{~mm}$ ) was the highest $\left(\mathrm{LA}=33.99 \mathrm{~mm}^{2}\right)$. 
Not only the MAT and MAP were climatic conditions that created selection pressure on LA but also high-radiation and air humidity (Dunbar-Co et al., 2009; PérezHarguindeguy et al., 2013). In particular, high-radiation tended to select for relative small leaves (Pérez-Harguindeguy et al., 2013; Uhl, Mosbrugger, 1999) to prevent overheating and confer a benefit in energy and/ or carbon balance (Vogel, 1968). Besides, leaf area correlated positively with minimum relative humidity (Dunbar-Co et al., 2009). Consequently, those climate factors could contribute in small leaves of Bidoup where had the highest annual sunshine duration (2133.25 hours) and the lowest annual air humidity $(83.33 \%)$. Otherwise, the largest leaves of Ngoc Linh could be due to the lower annual sunshine duration (1901.50 hours) as well as the highest annual air humidity (87.25\%). However, unlike MAT and MAP, Pearson's correlation test results did not show the significant correlations between LA and $\mathrm{SuH}(\mathrm{r}=-0.1178, \mathrm{P}=0.7153)$ or LA and $\mathrm{Hu}$ $(\mathrm{r}=0.5213, \mathrm{P}=0.0822)$.

The decrease of leaf width was consistent with temperature (Ezcurra et al., 1997). Therefore, the fluctuation of leaf width each year in each population showed a contrary trend with the fluctuation of average air temperature of each year. Besides, the trend mentioned above could be applied for the average measures of the four years. In particular, Hoang Lien distributing in cooler area $\left(15.77^{\circ} \mathrm{C}\right)$ had leaf width higher than that of Bidoup distributing in warmer area $\left(18.39^{\circ} \mathrm{C}\right)$. There was an exception in Ngoc Linh where had highest leaf width $(3.83 \mathrm{~mm})$ distributing in warmest area $\left(25.13^{\circ} \mathrm{C}\right)$. As Ngoc Linh has the highest rainfall over the four years $($ MAP $=4197.75 \mathrm{~mm})$, the promoting effect on leaf spreading of rainfall might overcame constraining effect of temperature. In conclusion, both temperature and rainfall had effect on leaf width of $H$. serrata. However, the effect of the two climatic factors had contrary trends.

An evolutionary trade-off between the antagonistic demand of maximizing photosynthesis relative to structural investment has yield a great diversity in the morphological character of leaves (Brodribb et al., 2010; Donovan et al., 2011). There were strong positive correlations between morphological leaf traits and temperature as well as rainfall.

\section{CONCLUSION}

Most of recorded morphological leaf traits were reveals that environment conditions have had the most important impacts on the favorable growing conditions. In this study, Quang Nam population, which is high MAT and MAP that exhibited increased growth (LL, LW and LA). Thus, as suggested that by leaf sizes increased with MAT and MAP.

Acknowledgements: This study was supported by the National Foundation for Science \& Technology Development (NAFOSTED) under grant no. 106-NN.032014.17. We also thank Mr. Nguyen Xuan Tung of Mangrove Ecosystem Research Centre (MERC)

Hanoi National University of Education (HNUE) for helping collecting samples and Mr. Nguyen Hoang Phong of Biology Faculty, Dalat University for helping preliminary accessing samples in laboratory.

\section{REFERENCES}

Abramoff M. D., Magalhães P., Ram J., Sunanda J., 2004. Image processing with ImageJ. Biophotonics International, 11(7): $36-43$.

Addinsoft., 2018. XLSTAT statistical and data analysis solution. New York, USA. https://www.xlstat.com. (Version 2018.1).

Arens N. C., 2001. Variation in performance of the tree fern Cyathea caracasana (Cyatheaceae) across a successional mosaic in an Andean cloud forest. American Journal of Botany, 88(3): 545551. https://doi.org/10.2307/2657118.

Brodribb T. J., Feild T. S., Sack L., 2010. Viewing leaf structure and evolution from a hydraulic perspective. Functional Plant Biology, 37(6): 488-498. https://doi.org/10.1071/FP10010. 
Geographical variation in morphological leaf traits

Choat B., Sack L., Holbrook N. M., 2007. Diversity of hydraulic traits in nine Cordia species growing in tropical forests with contrasting precipitation. New Phytologist, 175(4):

686-698. https://doi.org/10.1111/j.14698137.2007.02137.x.

Diaz S., Cabido M., Casanoves F., 1998. Plant functional traits and environmental filters at a regional scale. Journal of Vegetation Science, $\quad 9(1)$ : 113-122. https://doi.org/10.2307/3237229.

Donohue K., Messiqua D., Pyle H. E., Heschel M. S., Schmitt J., 2000. Evidence of adaptive divergence in plasticity: Density- and site-dependent selection on shade-avoidance responses in Impatiens capensis. Evolution, 54(6): 1956-1968. https://doi.org/10.1111/j.00143820.2000.tb01240.x.

Donovan L. A., Maherali H., Caruso C. M., Huber H., de Kroon H., 2011. The evolution of the worldwide leaf economics spectrum. Trends in Ecology \& Evolution, 26(2): $88-95$. https://doi.org/10.1016/j.tree.2010.11.011.

Dudley S. A., Schmitt J., 1996. Testing the Adaptive Plasticity Hypothesis: DensityDependent Selection on Manipulated Stem Length in Impatiens capensis. The American Naturalist, 147(3): 445-465. https://doi.org/10.1086/285860.

Dunbar C. S., Sporck M. J., Sack L., 2009. Leaf Trait Diversification and Design in Seven Rare Taxa of the Hawaiian Plantago Radiation. International Journal of Plant Sciences, 170(1): 61-75. https://doi.org/10.1086/593111.

Etterson J. R., Shaw R. G., 2001. Constraint to Adaptive Evolution in Response to Global Warming. Science, 294(5540): 151-154. https://doi.org/10.1126/science.1063656.

Ezcurra C., Ruggiero A., Crisci J. V., 1997. Phylogeny of Chuquiraga Sect. Acanthophyllae (AsteraceaeBarnadesioideae), and the Evolution of its
Leaf Morphology in Relation to Climate. Systematic Botany, 22(1): 151-163. https://doi.org/10.2307/2419683.

Feild T. S., Sage T. L., Czerniak C., Iles W. J. D., 2005. Hydathodal leaf teeth of Chloranthus japonicus (Chloranthaceae) prevent guttation-induced flooding of the mesophyll. Plant, Cell \& Environment, 28(9): 1179-1190. https://doi.org/10.1111/j.1365-

3040.2005.01354.x.

Flann C., Ladiges P. Y., Walsh N. G., 2002. Morphological variation in Leptorhynchos squamatus (Gnaphalieae: Asteraceae). Australian Systematic Botany, 15(2): 205-219.

Giełwanowska I., Szczuka E., Bednara J., Górecki R., 2005. Anatomical Features and Ultrastructure of Deschampsia antarctica (Poaceae) Leaves from Different Growing Habitats. Annals of Botany, 96(6): 1109-1119. https://doi.org/10.1093/aob/mci262.

Huang W., Zhao X., Zhao X., Li Y., Lian J., 2016. Effects of environmental factors on genetic diversity of Caragana microphylla in Horqin Sandy Land, northeast China. Ecology and Evolution, 6(22): 8256-8266. https://doi.org/10.1002/ece3.2549.

Jaswinder K., Rajmeet S., Gurinder S., Harpreet K., Jasvir K., Manpreet K, Jaspreet K., 2016. A Systematic Review on Huperzia serrata. International Journal of Pharmacognosy and Phytochemical Research, 8(8): 1250-1255.

Joshi J., Schmid B., Caldeira M. C., Dimitrakopoulos P. G., Good J., Harris R., Lawton J. H., 2001. Local adaptation enhances performance of common plant species. Ecology Letters, 4(6): 536-544. https://doi.org/10.1046/j.14610248.2001.00262.x.

Kessler M., Siorak Y., Wunderlich M., Wegner C., 2007. Patterns of morphological leaf traits among pteridophytes along humidity and 
temperature gradients in the Bolivian Andes. Functional Plant Biology, 34(11): 963-971. https://doi.org/10.1071/FP07087.

Li X., Li Y., Zhang Z., Li X., 2015. Influences of Environmental Factors on Leaf Morphology of Chinese Jujubes. PLOS ONE, 10(5): 1-16. https://doi.org/10.1371/ journal.pone.0127825.

Marcysiak K., 2012. Calculated characters of leaves are independent on environmental conditions in Salix herbacea (Salicaceae) and Betula nana (Betulaceae). Acta Societatis Botanicorum Poloniae, 81(3): $153-$

158.https://doi.org/10.5586/asbp.2012.027.

Pérez-Harguindeguy N., Díaz S., Garnier E., Lavorel S., Poorter H., Jaureguiberry P., Cornelissen J. H. C., 2013. New handbook for standardised measurement of plant functional traits worldwide. Australian Journal of Botany, 61(3): 167-234. https://doi.org/10.1071/BT12225.

Royer D. L., Wilf P., 2006. Why Do Toothed Leaves Correlate with Cold Climates? Gas Exchange at Leaf Margins Provides New Insights into a Classic Paleotemperature Proxy. International Journal of Plant Sciences, $167(1)$ : 11-18. https://doi.org/10.1086/497995.

Sack L., Cowan P. D., Jaikumar N., Holbrook N. M., 2003. The 'hydrology' of leaves: Co-ordination of structure and function in temperate woody species. Plant, Cell \& Environment, 26(8): 1343-1356. https://doi.org/10.1046/j.00168025.2003.01058.x.

Sack L., 2013. Holding a Leaf Up to the Light. BioScience, 63(12): 981-982. https://doi.org/10.1525/bio.2013.63.12.12.

Sultan S. E., 1995. Phenotypic plasticity and plant adaptation. Acta Botanica Neerlandica, 44(4): 363-383.
Traiser C., Klotz S., Uhl D., Mosbrugger V., 2005. Environmental signals from leaves - a physiognomic analysis of European vegetation. New Phytologist, 166(2): 465484. https://doi.org/10.1111/j.14698137.2005.01316.x.

Uhl D., Mosbrugger V., 1999. Leaf venation density as a climate and environmental proxy: A critical review and new data. Palaeogeography, Palaeoclimatology, Palaeoecology, 149(1): 15-26. https://doi.org/10.1016/S00310182(98)00189-8.

Vietnam Plant Data Center (BVNGroup). (n.d.). Retrieved April 25, 2016. Huperzia serrata. website: http://www.botanyvn.com/cnt.asp?param= edir $\& v=$ Huperzia $\% 20$ serrata\&list=species.

Villellas J., Berjano R., Terrab A., García M. B., 2014. Divergence between phenotypic and genetic variation within populations of a common herb across Europe. Ecosphere, 5(5): 1-14. https://doi.org/10.1890/ES13-00291.1.

Vogel S., 1968. "Sun Leaves" and "Shade Leaves": Differences in Convective Heat Dissipation. Ecology, 49(6): 1203-1204. https://doi.org/10.2307/1934517.

Wang D. L. , Qi Y. D., Feng J. D., Wei J. H., 2011. An Efficient Regeneration Pattern via Gemmae for Huperzia serrata (Thunb. Ex Murray) Trev. In Hainan Province, China. American Fern Journal, 101(3): 182-192. https://doi.org/10.1640/00028444-101.3.182.

Wright I. J., Reich P. B., Westoby M., Ackerly D. D., Baruch Z., Bongers F., Villar R., 2004. The worldwide leaf economics spectrum. Nature, 428(6985): 821-827. https://doi.org/10.1038/ nature 02403 . 